\title{
Mentalization-Based Treatment for Concurrent Borderline Personality Disorder and Substance Use Disorder: A Randomized Controlled Feasibility Study
}

\author{
Björn Philips $^{\mathrm{a}-c}$ Peter Wennberg ${ }^{\mathrm{d}, \mathrm{e}}$ Per Konradsson ${ }^{\mathrm{a}, \mathrm{b}}$ Johan Franck ${ }^{\mathrm{a}, \mathrm{b}}$

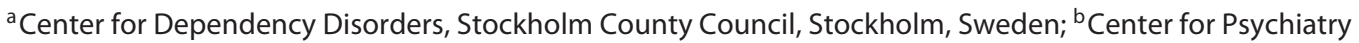 \\ Research, Department of Clinical Neuroscience, Karolinska Institutet, Stockholm, Sweden; 'Department of \\ Psychology, Stockholm University, Stockholm, Sweden; 'Centre for Social Research on Alcohol and Drugs, \\ Stockholm University, Stockholm, Sweden; ${ }^{e}$ Department of Public Health Sciences, Karolinska Institutet, Stockholm, \\ Stockholm, Sweden
}

\section{Keywords}

Psychotherapy · Borderline personality disorder ·

Substance-related disorders · Randomized controlled trial

\begin{abstract}
Aims: There is a scarcity of clinical trials on psychological treatments for concurrent borderline personality disorder (BPD) and substance use disorder (SUD). Mentalizationbased treatment (MBT) have shown efficacy in several trials on BPD. The aim of the present study was to examine the feasibility and effectiveness of MBT for concurrent BPD and SUD. Methods: Patients $(n=46)$ with concurrent BPD and SUD were randomized either to MBT in combination with SUD treatment $(n=24)$ or to SUD treatment alone $(n=22)$. Outcome was measured after 18 months using objective data, as well as interview and self-report measures. Results: There was no significant difference between the groups on any outcome variable. No suicide attempts occurred in the MBT group in contrast to 4 suicide attempts that occurred in the control group - a difference that did not reach statistical
\end{abstract}

\begin{tabular}{ll}
\hline KARGER & ( ) 2018 The Author(s) \\
Published by S. Karger AG, Basel Openger \\
E-Mail karger@karger.com & This article is licensed under the Creative Commons Attribution- \\
www.karger.com/ear & NonCommercial-NoDerivatives 4.0 International License (CC BY- \\
NC-ND) (http://www.karger.com/Services/OpenAccessLicense). \\
Usage and distribution for commercial purposes as well as any dis- \\
tribution of modified material requires written permission.
\end{tabular}

significance ( $p=0.06$ ). A majority of the therapists did not show sufficient MBT adherence and quality. Conclusion: MBT for patients with concurrent BPD and SD does not appear to be harmful; on the other hand, it is possibly helpful in reducing the risk involved in suicide attempts.

(c) 2018 The Author(s)

Published by S. Karger AG, Basel

\section{Introduction}

Borderline personality disorder (BPD) and substance use disorder (SUD) are both severe psychiatric disorders associated with impaired functioning and increased risk of suicide and premature death [1-3]. Concurrent BPD and SUD indicates even more severity and complexity and such co-morbidity is associated with additionally increased rates of suicidal and self-harming behaviour [46]. Patients with this dual diagnosis offer a challenge for treatment providers and there is widespread pessimism among practitioners about the possibilities of successful

Assoc. Prof. Björn Philips Department of Psychology Stockholm University

SE-106 91 Stockholm (Sweden)

E-Mail bjorn.philips@ psychology.su.se 
treatment [7-9]. The prevalence of SUD among patients diagnosed with BPD has been estimated to be over $50 \%$ [10]. Among patients treated for dependence on illicit drugs, the occurrence of co-morbid BPD has been estimated to $18 \%$ [11].

Although the research literature is extensive on the efficacy of several psychological therapies for BDP [12] and for SUD [13-17] separately, studies focusing on treatment for concurrent BDP and SUD are still scarce. A recent systematic review of psychological treatments for cooccurring SUD and BPD included 10 studies, examining 3 different interventions: dialectical behaviour therapy (DBT), dynamic deconstructive psychotherapy (DDP) and dual-focused schema therapy [18]. However, only 3 of these studies were original reports on randomized controlled trials (RCT) with inclusion criteria of co-occurring BPD and SUD. Two studies examined the effect of DBT in combination with medication, both including only female patients and both with small sample sizes $(n=$ 28 and $n=23$ respectively) $[19,20]$. These studies indicated some advantages in outcome of DBT combined with medication, compared to treatment as usual (TAU) [19] and compared to comprehensive validation therapy with 12-step (CVT + 12S) [20]. In the first trial, $42 \%$ of the patients in DBT terminated prematurely [19]. In the second trial, the dropout rate in DBT was $36 \%$ compared to no dropout in CVT $+12 S$ [20]. The third RCT $(n=30)$ included both female and male patients in DDP, a type of psychodynamic therapy especially designed for patients with severe personality disorders, and the study showed that improvements were larger in DDP than in TAU [21]. The dropout rate in DDP was 33\% [21]. The RCTs conducted on DSFT included patients with SUD and a mixture of different personality disorders, and the studies provided no empirical support for the effectiveness of DSFT $[22,23]$. Very high dropout rates were noted in these trials testing dual-focused schema therapy $-77 \%$ for homeless dual diagnosis patients [22] and 58\% for patients in residential treatment [23].

Mentalization-based treatment (MBT) is a contemporary psychodynamic therapy developed primarily for BPD [24]. Mentalization refers to the capacity to apprehend and make sense of oneself and other humans in terms of subjective states and mental processes, and MBT is based on research findings indicating that recurrent mentalization failures is a core feature among individuals with BPD $[25,26]$. MBT for BPD is typically delivered as a combination of individual and group therapy weekly during 18 months and it aims at strengthening the patients mentalizing capacity in order to reduce the BPD core problems such as poor impulse control, emotional instability, impaired interpersonal functioning, unstable self-concept and self-destructiveness [27]. MBT have been tested in 3 RCTs for adult patients with BPD. The first study $(n=36)$ compared MBT to standard psychiatric care and MBT was superior at termination on all outcome measures, including suicide attempts, self-harm and depression, as well as days of hospitalization and social functioning [28]. The effects of MBT maintained 5 years after termination [29]. The second study $(n=134)$ compared MBT to structured clinical management and MBT was superior at termination on all outcome measures, including suicide attempts, self-harm and psychiatric symptoms, as well as days of hospitalization [30]. The third study ( $n=85$ ) compared MBT to supportive group therapy and MBT was only superior on the global assessment of functioning, while there were clear improvements in both treatments with no significant within-group effects on neither of the other measures [31]. In addition, one study tested MBT for adolescents with depression and self-harming behaviour $(n=80)$ with TAU as control condition, and the results showed that MBT had superior outcomes on depression and self-harm [32].

Bateman and Fonagy's trials of MBT for BPD included substantial proportions of patients with co-morbid SUD, 46 and $41 \%$ respectively $[28,30]$. MBT has been adapted to patients with concurrent BPD and SUD treated within substance dependence care in Bergen, Norway, and the treatment was tested in an open trial ( $n=15$; all females). The results were promising with substantial decrease of substance dependence, as well as improvements on global functioning, psychiatric symptoms and interpersonal functioning [33]. The project in Bergen also resulted in a qualitative study of the patients' experiences of change in MBT [34]. However, until the present study, MBT for concurrent BPD and SUD had not been tested in an RCT.

The present study aimed to examine the feasibility and effectiveness of MBT in combination with standard SUD treatment, compared to standard SUD treatment alone, for patients with concurrent BPD and SUD. All treatments were delivered in the context of regular addiction treatment services within the public sector in Sweden.

\section{Methods}

This research project, MBT for Dual Diagnosis - A RCT was a registered clinical trial (ISRCTN 98982683) approved by the Stockholm Regional Ethical Review Board (Registration number: 2007/642-31/1). All subjects gave their informed consent for participation. The trial was conducted at the Stockholm Centre for 
Dependency Disorders, Stockholm County Council, in collaboration with the Centre for Psychiatry Research at Karolinska Institutet. Patients were recruited through outpatient addiction treatment services throughout Stockholm County, through case-finding among the social service offices in the region and through advertising in newspapers. The study was originally planned to include $80(40+40)$ patients, based on a power calculation. However, due to the slow rate of patient enrollment and lack of economical recourses, the inclusion period had to stop prematurely at $n=46$. Accordingly, focus of the study shifted from efficacy to feasibility and effectiveness. The principal investigator (PI) was responsible for the study being conducted in accordance to the Helsinki Declaration (revised version from 2000) and Good Clinical Practice (GCP). The study was monitored by the Karolinska Trial Alliance (KTA) in accordance to ICH-GCP.

Patients were screened and included between 2009 and 2013, which means that the last patient reached the study endpoint in 2015. Inclusion criteria were males and females aged 18-65 years, fulfilling diagnostic criteria for BPD and substance dependence in accordance with the Diagnostic and Statistical Manual of Mental Disorders, 4th Edition (DSM-IV) [35], and currently undergoing treatment at a substance dependence treatment clinic. Exclusion criteria were schizophrenia, schizoaffective disorder, bipolar disorder type I, cognitive impairment (including mild cognitive impairment: IQ <85), autism spectrum disorders, psychopathy, participation in psychotherapy outside of the study (ongoing or terminated less than 90 days before inclusion) and not being able to communicate in the Swedish language without an interpreter.

The study was a randomized controlled trial with 2 parallel arms, in which efforts were made to keep external raters unaware of the patient's treatment assignment. The randomization was conducted by the KTA using an urn procedure. The randomization was made in blocks and the researchers were not informed of the block size. KTA prepared sealed randomization envelopes with information about each patient's treatment assignment. The project received 248 referrals, of which 84 patients were assessed for eligibility and 46 of them included in the trial as described in the flow diagram in Figure 1.

After inclusion, patients were randomized to either of 2 treatment arms - (1) MBT during 18 months as a complement to standard SUD treatment (2) standard SUD treatment alone.

\section{Patients}

Of the 46 included patients, 24 were randomized to MBT and 22 were randomized to the control condition. The mean age at inclusion was 36.7 (SD 9.6), in the range from 20 to 54 years. Other patient characteristics including psychiatric diagnoses are described in Table 1.

\section{Treatment and Therapists}

The MBT included a combination of individual therapy and group therapy during 18 months. The MBT therapists worked together in a team with regular supervision and team meetings, in which the therapists shared information about the patients and discussed their mutual therapeutic work.

Nine therapists participated in the trial - 7 females and 2 males, aged 44-60 when the project began. All therapists had at least basic psychotherapy training with psychodynamic orientation, and 7 of them also had advanced psychotherapy training, they being Swed-

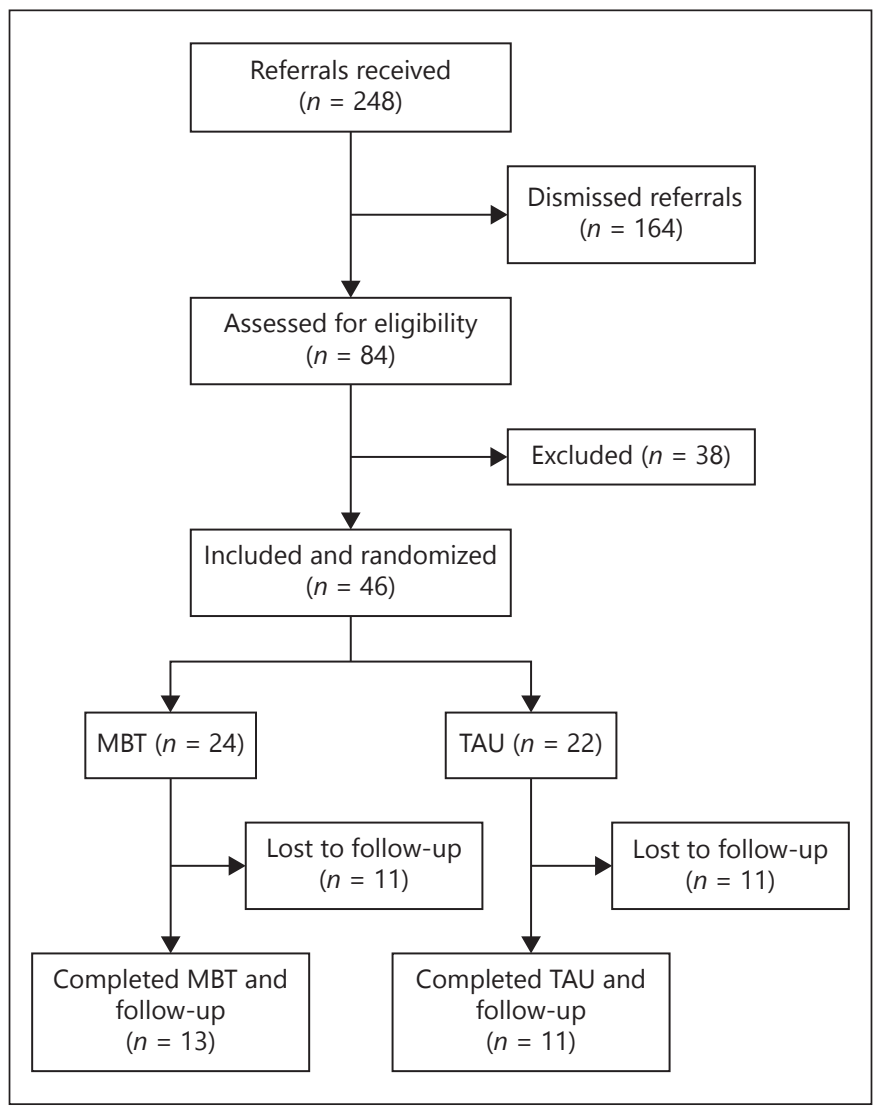

Fig. 1. CONSORT flow diagram for Mentalization-Based Treatment for Dual Diagnosis (MBTDD) - a randomized controlled trial.

ish licensed psychotherapists. As for the professional background, 3 were psychologists, 3 were social workers, 1 was a nurse and 2 were psychiatric aides. They all had several years of experience in working with SUD as well as MBT training in the form of the MBT Basic Course (3 days) taught by Anthony Bateman and Peter Fonagy. Before entering the project, all therapists conducted a training treatment that was videotaped, judged for treatment integrity using version 4 of the MBT adherence scale and approved by MBT supervisors and the project leader. During the project, 3 therapists conducted both individual and group therapy, 5 conducted only individual therapy and 1 conducted only group therapy. The therapists were in MBT supervision once a week during the project period. Samples of individual therapy sessions from the project were tested by independent raters for therapist MBT adherence and quality using the final version of the scale [36].

\section{Measures}

The patients' diagnoses on DSM-IV Axes I and II were established using the Structured Clinical Interview for DSM-IV Disorders I (SCID-I) [37] and II (SCID-II) [38].

Screening for cognitive impairment was done using the subscales Vocabulary and Block Design from Wechsler Adult Intelligence Scale - 3rd edition [39]. The results on these 2 subtests have shown correlation of $r=0.90$ with total intelligence quote [40, 41]. 
Table 1. Patient characteristics at inclusion $(n=46)$

\begin{tabular}{lrr}
\hline Characteristic & $n$ & $\%$ \\
\hline Female & 37 & 80.4 \\
Married/living together with partner & 13 & 28.2 \\
Has children & 24 & 52.2 \\
Tertiary education started & 12 & 26.1 \\
Employed or student & 7 & 15.2 \\
Born in Sweden & 39 & 84.8 \\
\hline Current axis I psychiatric disorder & & \\
Major depressive disorder & 13 & 28.3 \\
Other depressive disorder including dysthymia & 13 & 28.3 \\
Bipolar II & 3 & 6.5 \\
PTSD & 7 & 15.2 \\
Any anxiety disorder excluding PTSD & 30 & 65.2 \\
Any eating disorder & 3 & 6.5 \\
Somatoform disorder & 1 & 2.2 \\
Any psychotic disorder & 0 & 0 \\
\hline Current axis I substance use disorder & & \\
Alcohol & 21 & 45.7 \\
Amphetamines & 6 & 13.0 \\
Cannabis & 3 & 6.5 \\
Opioids & 18 & 39.1 \\
Sedatives, hypnotics, anxiolytics & 10 & 21.7 \\
\hline Current axis II personality disorder & & \\
Paranoid & 9 & 19.6 \\
Schizoid & 10 & 21.7 \\
Schizotypal & 46 & 100 \\
Antisocial & 6 & 2.2 \\
Borderline & 6 & 13.0 \\
Histrionic & 6 & 13.0 \\
Narcissistic & 3 & 6.5 \\
Avoidant & 6 & 13.0 \\
Dependent & 19.6 \\
Obsessive compulsive & & \\
Depressive & & \\
Passive aggressive & & \\
\hline & & \\
\hline
\end{tabular}

PTSD, posttraumatic stress disorder.

Screening for autism spectrum disorders was done using the Autistic-Spectrum Quotient (AQ) [42].

Patients who fulfilled criteria for either antisocial or narcissistic personality disorder were screened for psychopathy using the Psychopathy Checklist: Screening Version [43].

The BPD Severity Index-IV (BPDSI-IV) was used to yield a quantitative index of the current severity of BPD symptoms. The measure assesses BDP manifestations in detail, within the last 3 months. The semi-structured interview consists of 70 questions, arranged into 9 subscales representing the 9 BPD criteria in DSM-IV. The measure has demonstrated good psychometric properties (Cronbach's $\alpha=$ 0.86 ; ICC $=0.98$ ), good validity and sensitivity to change [44].

Timeline Follow Back (TLFB) was used for collecting the patient's retrospective estimation of his or her use of alcohol and drugs day by day backwards in time [45]. Patients were interviewed about their use of alcohol and drugs during the last 30 days. Alcohol use was operationalized as 2 variables: number of drinking days and number of days with heavy episodic drinking (HED; $\geq 60 \mathrm{~g}$ alcohol/day for males, $\geq 45 \mathrm{~g}$ alcohol/day for females). Drug use was operationalized as number of days with any drug use.

The frequency of deliberate self-harm behaviour was investigated using the short version of the self-report scale Deliberate Self-Harm Inventory (DSHI-9) [46] in a Swedish translation that has shown satisfactory reliability [47].

Psychiatric symptoms were measured with the Swedish version of the Symptom Checklist-90-Revised [48, 49], which has shown a satisfactory reliability (Cronbach's $\alpha=0.97$ ) [50]. As the 9 subscales are highly correlated, the Global Symptom Index (GSI) was used as an aggregate measure.

Interpersonal problems were investigated using a shortened version (64 items) of the self-report scale Inventory of Interpersonal Problems (IIP) [51]. The total mean score was used as a global measure of the level of interpersonal problems.

Reflective functioning (RF) as measured with the Reflective Functioning Scale [52] was used to assess the level of explicit mentalizing about attachment relationships. These assessments were based on the Brief Reflective Functioning Interview, which is a semi-structured interview including 11 questions about the relationship with one parent and one current important relationship $[53,54]$.

Measurements were conducted at baseline (screening and inclusion visits) and after 6,12 and 18 months. Endpoint was after 18 months, which signified termination of MBT treatments. Except for the screening instruments (SCID-I and II, Wechsler Adult Intelligence Scale - 3rd edition, AQ and Psychopathy Checklist: Screening Version) only used at baseline, the same set of measures were used at all 4 time points (baseline, 6, 12 and 18 months) - that is, BPDSI-IV, TLFB, DSHI-9, Symptom Checklist-90-Revised, IIP and RF. At endpoint after 18 months, SCID-I and II interviews were repeated.

Three additional outcome variables were used based on objective data: Number of adverse events (AE), suicide attempts specifically, and days in inpatient care. The type of events defined as AEs included relapse in substance abuse, overdose and psychiatric or somatic illness, as well as violent acts and self-harm behaviour. Suicide attempts and other AE were recorded via direct contact with patients and health care staff, as well as from reviewing the case records. As the responsibility for treatment of substance abusers in Sweden is shared by the health care system organized under the county councils and the social services, inpatient care for SUD patients could take place at addiction treatment services and psychiatric clinics (both belonging to the health care system), as well as treatment facilities operating under the social services. Number of days of inpatient care was monitored for each patient during the study. The number of days of hospitalization within the health care system were controlled and adjusted retrospectively through collecting data from the Stockholm County Council's registers.

\section{Statistical Analysis}

The original power calculation was based on the power table provided by Kazdin [55]. For the between-group effect, we expected at least $d=0.7$, which meant that with $80 \%$ power and $\alpha=0.05$ each arm should include 33 patients. As we expected $20 \%$ attrition, we decided that the trial should include $40+40$ patients. Due to the recruitment problems in the project, our initial power calculation had to be revised. The power was approximately $65 \%$, given $n=$ 
Table 2. Outcome for MBT versus control group, completer analysis

\begin{tabular}{|c|c|c|c|c|c|c|c|c|c|}
\hline \multirow[t]{2}{*}{ Measure } & \multicolumn{2}{|c|}{$\operatorname{MBT}(n=12-13)$} & \multicolumn{2}{|c|}{ Control $(n=10-13)$} & \multirow[t]{2}{*}{ Effect of time } & \multirow[t]{2}{*}{$\begin{array}{l}\text { Effect of } \\
\text { time } \times \text { treatment }\end{array}$} & \multicolumn{3}{|c|}{$\begin{array}{l}\text { Effect sizes } \\
\text { (positive values between groups } \\
\text { in favour of MBT, positive } \\
\text { values within group reflects } \\
\text { improvement over time) }\end{array}$} \\
\hline & pre & post & pre & post & & & Cohen's d & $\begin{array}{l}\text { within } \\
\text { MBT } \\
\text { group }\end{array}$ & $\begin{array}{l}\text { within } \\
\text { control } \\
\text { group }\end{array}$ \\
\hline BPDSI-IV & $24.6(10.4)$ & $17.0(9.1)$ & $25.8(6.6)$ & $20.7(9.1)$ & $\mathrm{F}(1,24)=12.9, p=0.001$ & $\mathrm{~F}(1,24)=0.46, \mathrm{~ns}$ & 0.41 & 0.78 & 0.65 \\
\hline Drinking, days & $1.6(2.3)$ & $9.1(9.9)$ & $0.5(1.3)$ & $2.8(4.4)$ & $\mathrm{F}(1,21)=7.9, p=0.01$ & $\mathrm{~F}(1,21)=2.3, \mathrm{~ns}$ & -0.88 & -1.23 & -0.81 \\
\hline $\begin{array}{c}\text { Days with any } \\
\text { drug use }\end{array}$ & $0.08(0.29)$ & $1.3(3.0)$ & $0.90(0.30)$ & $0.18(0.60)$ & $\mathrm{F}(1,21)=2.0, \mathrm{~ns}$ & $\mathrm{~F}(1,21)=1.5, \mathrm{~ns}$ & -0.62 & -0.74 & 1.60 \\
\hline GSI & $1.3(0.83)$ & $2.0(0.71)$ & $1.5(0.49)$ & $1.9(0.32)$ & $\mathrm{F}(1,23)=34.1, p<0.001$ & $\mathrm{~F}(1,23)=1.9, \mathrm{~ns}$ & -0.19 & -0.91 & -0.82 \\
\hline IIP & $2.0(0.62)$ & $1.5(0.54)$ & $2.2(0.60)$ & $1.7(0.56)$ & $\mathrm{F}(1,24)=58.0, p<0.001$ & $\mathrm{~F}(1,24)=0.48, \mathrm{~ns}$ & 0.36 & 0.86 & 0.86 \\
\hline DSHI-9 & $1.8(3.6)$ & $2.3(5.5)$ & $3.2(4.4)$ & $2.2(4.8)$ & $\mathrm{F}(1,24)=0.11, \mathrm{~ns}$ & $\mathrm{~F}(1,24)=0.78, \mathrm{~ns}$ & -0.02 & -0.11 & 0.22 \\
\hline RF & $3.3(1.2)$ & $2.8(1.2)$ & $4.2(1.3)$ & $3.8(1.6)$ & $\mathrm{F}(1,20)=2.7, \mathrm{~ns}$ & $\mathrm{~F}(1,20)=0.09, \mathrm{~ns}$ & -0.71 & -0.42 & -0.28 \\
\hline
\end{tabular}

ns, non-significant.

$22+24$ patients and the assumptions of $d=0.7$ and $\alpha=0.05$. MannWhitney $U$ test was used for outcome analyses of ordinal or not normally distributed variables. Analysis of variance with repeated measurements was used for outcome analyses of interval variables.

\section{Results}

\section{Treatment Retention and Dosage}

For patients randomized to MBT $(n=24)$, the treatment duration was in average 15.5 months (SD 4.1, range 3-18) with a mean of 63.3 MBT sessions (SD 26.7, range $10-116)$. Of the patients randomized to the control group $(n=22), 11$ received some sort of psychotherapy (CBT, MI, PDT, MBT [one patient], mindfulness group, supportive therapy). Control group patients received on average 10.7 therapy sessions (SD 14.7, range $0-45$ ).

\section{Outcome on Objective Measures}

In the intention-to-treat (ITT) analysis, 4 suicide attempts occurred (committed by 3 patients) in the control group in contrast to no suicide attempt in the MBT group. A comparison between the groups using Mann-Whitney $\mathrm{U}$ test showed only a trend towards significance $(p=$ $0.06)$. No patient died during the study. The number of $\mathrm{AE}$ was 33 in the MBT group (with maximum of $5 \mathrm{AE}$ per patient) and the corresponding number of $\mathrm{AE}$ in the control group was 53 (with a maximum of $10 \mathrm{AE}$ per patient). However, comparing the groups using Mann-Whitney $\mathrm{U}$ test revealed no significant difference $(p=0.40)$. In the MBT group $(n=24), 11$ patients had a few days of hospi- talization with an average of 16.2 days (SD 37.6, range $0-151)$, and in the control group $(n=22), 7$ patients had a few days of hospitalization, with the average of 33.2 days (SD 68.5, range 0-237). However, a comparison between the groups showed no significant difference $(p=0.74)$.

\section{Outcome on Self-Report and Interview Measures}

Outcome analyses were made both in the form of completer analyses and ITT analysis with the last observation carried forward. Throughout all measures, completer and ITT analyses gave equivalent results and therefore only the results from completer analyses are described here (Table 2). Outcome analyses of the self-report and interview measures were seriously challenged by the high attrition rates, as only 24 out of 46 patients came to the measurements at endpoint 18 months ( 13 out of 24 patients in MBT, and 11 out of 22 patients in the control group).

With regard to severity of BPD in terms of BPDSI-IV, there was a significant effect of time $(\mathrm{F}[1,24]=12.9$; $p=$ 0.001) showing improvements in both the MBT and the control conditions. However, there was no significant difference between the conditions, as shown by the lack of effect of time $\mathrm{x}$ treatment $(\mathrm{F}[1,24]=0.46 ; p=0.50)$. As for alcohol use, the results on the number of drinking days showed a significant effect of time $(\mathrm{F}[1,21]=7.9 ; p=0.01)$ indicating increased drinking in both groups. There was no effect on time $\times$ treatment $(F[1,21]=2.3 ; p=0.15)$, indicating no significant difference between $\mathrm{MBT}$ and control condition. Also, for heavy episodic drinking (HED), there was a significant effect of time $(\mathrm{F}[1,21]=8.2 ; p=$ 0.01 ) showing increase of binge drinking in both groups. 
No effect of time $\times$ treatment $(\mathrm{F}[1,21]=1.4 ; p=0.26)$ was detected. No significant changes were detected regarding deliberate self-harm, as indicated by no effect of time on DSHI-9 $(F[1,24]=0.11 ; p=0.75)$. The treatment conditions did not significantly differ on DSHI-9, which was shown in the absence of effect of time $\times$ treatment $(\mathrm{F}[1$, $24]=0.78 ; p=0.39$ ). As for psychiatric symptoms, the results on GSI showed a significant effect of time $(F[1,23]=$ 34.1; $p<0.001)$ indicating increased symptom distress in both conditions. There was no significant difference on GSI between MBT and control condition as indicated by no effect of time $\times$ treatment $(F[1,23]=1.9 ; p=0.18)$. Interpersonal problems decreased in both conditions as indicated by a significant effect of time on IIP $(F[1,24]=$ 58.0; $p<0.001)$. However, the absence of a significant effect of time $\times$ treatment on $\operatorname{IIP}(\mathrm{F}[1,24]=0.48, p=0.50)$ showed that the 2 treatment conditions did not differ on this measure. In addition, mentalizing capacity as measured with $\mathrm{RF}$ remained unchanged in both conditions as indicated by no effect of time $(\mathrm{F}[1,20]=2.7 ; p=0.12)$. There was no significant difference between the treatment conditions regarding $\mathrm{RF}$ as shown by the non-significant effect of time $\times$ treatment $(\mathrm{F}[1,20]=0.09, p=0.76)$.

As the therapists varied in MBT adherence and quality, we tested if these factors were related to outcome. However, change in severity of BPD among patients in the MBT arm was not significantly correlated with therapist average MBT adherence and quality. Furthermore, we tested whether change in severity of BPD among patients in the MBT arm was related with the number of MBT-sessions, but the correlation was not significant.

As about half of the patients were lost to follow-up in both the MBT and the control group, we found it important to test whether there was any systematic difference between the groups with regard to which patient completed and which patient dropped out. We investigated the difference between completers and dropouts, separately for the MBT and the control group, based on a number of baseline features that could have a major prognostic impact - gender, age, initial reflective functioning, opiate dependence, cluster A PD, antisocial PD, number of PDs and AQ score. No significant difference was found between completers and dropouts in neither MBT nor the control group.

\section{MBT Adherence and Quality}

Despite significant efforts to train and supervise the therapists in the MBT model, most of the them had poor average results on the MDT adherence tests: only 2 therapists passed the threshold for adequate MBT, while the remaining 7 failed to do so [56].

\section{Discussion}

The present study is the largest randomized controlled trial of a psychological treatment for patients with concurrent BPD and SUD carried out up to this date, with a final sample size of $n=46$. However, the sample size is smaller than the pre-established recruitment target and similar to previous studies with this patient population, the present study had high attrition and low attendance in therapy as its major limitations. Given that the study targeted a group with a severe psychiatric co-morbidity with high incidence of suicide-related behaviours, it is noteworthy that no patient died during the study. Furthermore, in contrast to 4 suicide attempts among the patients with standard SUD treatment alone, there were no suicide attempts in the MBT group - a difference that was close to statistical significance. In addition, there was no indication that MBT increased the occurrence of AEs or days of hospitalization. With regard to outcome based on self-report and interview measures, no significant differences were detected between the intervention and the control group.

Limitations of the present study include the suboptimal MBT adherence and quality, and the small sample size with high attrition. These shortcomings severely affect the internal validity of the study. The missing advantage of MBT compared to standard SUD treatment might be caused by the insufficient MBT performance of the employed therapists. It is a challenging task to treat dual diagnosis patients, but the therapists' suboptimal MBT adherence might also be affected by shortcomings in the organizational implementation of MBT. For example, the MBT team was larger than recommended, the MBT therapists devoted too few hours per week to MBT, and the MBT team lacked the specific functions of a team manager, social counsellor and nurse. The fact that half of the patients in the control group received some form of psychotherapy also decreased the internal validity. The reduction of the sample size from planned $n=80$ to actual $n=46$ did not only decrease the statistical power but also increased the risk for heterogeneity between the groups with regard to baseline features. Low statistical power increases the risk for both types 1 and 2 errors. Patients with BPD and co-morbidity of any SUD present a large heterogeneity, which increases the need for a large sample size for reducing the risk of the outcome being affected by confounding variables and large variance in the dependent variables. 
The strengths of the study include its randomized controlled design; continuous independent monitoring; a combination of interview/self-report measures and register outcomes; and adherence to ICH-GCP. The study focused on patients with a specific psychiatric co-morbidity, for which there are few treatment outcome studies, and it is the first randomized controlled trial of MBT for this patient population. Furthermore, the trial was conducted in a naturalistic clinical context in a public addiction clinic, which adds to its external validity.

The results of the present study indicate that MBT in combination with standard SUD treatment for patients with concurrent BPD and SUD has no harmful effect and might be helpful in reducing risk for suicide attempts. MBT was conducted with suboptimal adherence to the treatment principles and was not found to be significantly more effective than the control condition on a range of self-report and interview measures. The attendance in therapy was low and the frequency of premature termination was high, which is in agreement with the results of previous studies with similar patient populations [1923]. Thus, MBT had no significantly better effect on therapy retention than previously employed interventions. The data from the present study will be made available for meta-analyses of the effectiveness of MBT in BPD/SUD following the completion of future trials.

\section{Acknowledgements}

MBT training and consultation throughout the project was provided by Professor Anthony Bateman and Professor Peter Fonagy, University College London, London, UK. The following external experts contributed to the planning of the project: Professor Jacques Barber Adelphi University, NJ, Professor Pierre LaFolie, Karolinska Institutet, Stockholm, Sweden, Dr. Göran Rydén, Stockholm County Council, Stockholm, Sweden, Professor Rolf Sandell, Lund and Professor Lars-Göran Öst, Stockholm. We want to express our gratitude to the former head of the Stockholm Centre for Dependency Disorders, Dr. Stefan Borg, for giving us the opportunity to initiate and carry out the study. The project was skillfully coordinated by Charlotte Vedin, Moa Isaksson, Karin Lindqvist and Jakob Mechler. All assessors, therapists and the MBT supervisors are gratefully acknowledged.

\section{Disclosure Statement}

The authors have no conflicts of interest to declare.

\section{Funding Source}

This work was supported by the Swedish Research Council for Health, Working Life and Welfare (grant number 2007-0457); by ALF-funding from Stockholm County Council and Karolinska Institutet, Stockholm, Sweden (grant number 20080487); and by the Stockholm Centre for Dependency Disorders.

\section{References}

1 Chesney E, Goodwin GM, Fazel S: Risks of all-cause and suicide mortality in mental disorders: a meta-review. World Psychiatry 2014; 13:153-160.

2 Cheng AT, Chen TH, Chen CC, Jenkins R: Psychosocial and psychiatric risk factors for suicide. Case-control psychological autopsy study. Br J Psychiatry 2000;177:360-365.

3 Youdelis-Flores C, Ries RK: Addiction and suicide: a review. Am J Addict 2015;24:98104.

4 Hjorthøj C, Østergaard ML, Benros ME, et al: Association between alcohol and substance use disorders and all-cause and cause-specific mortality in schizophrenia, bipolar disorder, and unipolar depression: a nationwide, prospective, register-based study. Lancet Psychiatry 2015;2:801-808.

5 Steingrimsson S, Sigurdsson MI, Aspelund T, Sigfusson S, Magnusson A: Total populationbased study of the impact of substance use disorders on the overall survival of psychiatric inpatients. Nord J Psychiatry 2016;70:161166.

6 Østergaard ML, Nordentoft M, Hjorthøj C: Associations between substance use disorders and suicide or suicide attempts in people with mental illness: a Danish nation-wide, prospective, register-based study of patients diagnosed with schizophrenia, bipolar disorder, unipolar depression or personality disorder. Addiction 2017;112:1250-1259.

7 Back SE, Waldrop AE, Brady KT: Treatment challenges associated with comorbid substance use and posttraumatic stress disorder: clinicians' perspectives. Am J Addict 2009;18: 15-20.

8 Bourke ME, Grenyer BF: Psychotherapists' response to borderline personality disorder: a core conflictual relationship theme analysis. Psychother Res 2010;20:680-691.

9 Cournoyer LG, Brochu S, Landry M, Bergeron $\mathrm{J}$ : Therapeutic alliance, patient behaviour and dropout in a drug rehabilitation programme: the moderating effect of clinical subpopulations. Addiction 2007;102:1960-1970.

10 Trull TJ, Sher KJ, Minks-Brown C, Durbin J, Burr R: Borderline personality disorder and substance use disorders: a review and integration. Clin Psychol Rev 2000;20:235-253.

11 Verheul R: Co-morbidity of personality disorders in individuals with substance use disorders. Eur Psychiatry 2001;16:274282.

12 Stoffers J, Völlm BA, Rücker G, Timmer A, Huband N, Lieb K: Psychological therapies for people with borderline personality disorder. Cochrane Database Syst Rev 2012; 8:CD005652.

13 Amato L, Minozzi S, Davoli M, Vecchi S: Psychosocial combined with agonist maintenance treatments versus agonist maintenance treatments alone for treatment of opioid dependence. Cochrane Database Syst Rev 2011; 5;10:CD004147.

14 Darker CD, Sweeney BP, Barry JM, Farrell MF, Donnelly-Swift E: Psychosocial interventions for benzodiazepine harmful use, abuse or dependence. Cochrane Database Syst Rev 2015; 5:CD009652.

15 Gates PJ, Sabioni P, Copeland J, Le Foll B, Gowing L: Psychosocial interventions for cannabis use disorder. Cochrane Database Syst Rev 2016;5:CD005336.

16 Martin GW, Rehm J: The effectiveness of psychosocial modalities in the treatment of alcohol problems in adults: a review of the evidence. Can J Psychiatry 2012;57:350-358. 
17 Darker CD, Sweeney BP, Barry JM, Farrell MF, Donnelly-Swift E: Psychosocial interventions for benzodiazepine harmful use, abuse or dependence. Cochrane Database Syst Rev 2015;5:CD009652.

18 Lee NK, Cameron J, Jenner L: A systematic review of interventions for co-occurring substance use and borderline personality disorders. Drug Alcohol Rev 2015;34:663-672.

19 Linehan MM, Schmidt H 3rd, Dimeff LA, Craft JC, Kanter J, Comtois KA: Dialectical behavior therapy for patients with borderline personality disorder and drug-dependence. Am J Addict 1999;8:279-292.

20 Linehan MM, Dimeff LA, Reynolds SK, Comtois KA, Welch SS, Heagerty P, Kivlahan DR: Dialectical behavior therapy versus comprehensive validation therapy plus 12 -step for the treatment of opioid dependent women meeting criteria for borderline personality disorder. Drug Alcohol Depend 2002;67:1326.

21 Gregory RJ, Chlebowski S, Kang D, Remen AL, Soderberg MG, Stepkovitch J, Virk S: A controlled trial of psychodynamic psychotherapy for co-occurring borderline personality disorder and alcohol use disorder. Psychotherapy 2008;45:28-41.

22 Ball SA, Cobb-Richardson P, Connolly AJ, Bujosa CT, O'Neall TW: Substance abuse and personality disorders in homeless drop-in center clients: symptom severity and psychotherapy retention in a randomized clinical trial. Compr Psychiatry 2005;46:371-379.

23 Ball SA, Maccarelli LM, Lapaglia DM, Ostrowski, MJ: Randomized trial of dual-focused versus single-focused individual therapy for personality disorders and substance dependence. J Nerv Ment Dis 2011;199:319328.

24 Bateman AW, Fonagy P: Psychotherapy for Borderline Personality Disorder: Mentalization-Based Treatment. Oxford, Oxford University Press, 2004.

25 Fonagy P, Bateman AW: Mentalizing and borderline personality disorder. J Ment Health 2007;16:83-101.

26 Fonagy P, Luyten P: A developmental, mentalization-based approach to the understanding and treatment of borderline personality disorder. Dev Psychopathol 2009;21:13551381.

27 Bateman AW, Fonagy P: Mentalization-based treatment for personality disorders: a practical guide. Oxford, Oxford University Press, 2016.

28 Bateman AW, Fonagy P: Effectiveness of partial hospitalization in the treatment of borderline personality disorder: a randomized controlled trial. Am J Psychiatry 1999;156:15631569.

29 Bateman AW, Fonagy P: 8-Year follow-up of patients treated for borderline personality disorder: mentalization-based treatment ver- sus treatment as usual. Am J Psychiatry 2008; 165:631-638.

30 Bateman AW, Fonagy P: Randomized controlled trial of outpatient mentalization-based treatment versus structured clinical management for borderline personality disorder. Am J Psychiatry 2009;166:1355-1364.

31 Jørgensen CR, Freund C, Bøye R, Jordet $H$, Andersen D, Kjølbye M: Outcome of mentalization-based and supportive psychotherapy in patients with borderline personality disorder: a randomized trial. Acta Psychiatr Scand 2013;127:305-317.

32 Rossouw TI, Fonagy P: Mentalization-based treatment for self-harm in adolescents: a randomized controlled trial. J Am Acad Child Adolesc Psychiatry 2012;51:1304-1313.

33 Arefjord N: Mentaliseringsbasert terapi (MBT) til rusavhengige kvinnelige pasienter med emosjonell ustabil personlighetsforstyrrelse [Mentalization-based treatment (MBT) for female patients with emotionally instable personality disorder]. Bergen, Stiftelsen Bergenklinikkene, 2013.

34 Morken KTE, Binder PE, Arefjord N, Karterud S. Juggling thoughts and feelings: how do female patients with borderline symptomology and substance use disorder experience change in mentalization-based treatment? Psychother Res 2017;1-16.

35 American Psychiatric Association: Diagnostic and Statistical Manual of Mental Disorders, ed 4. Washington, American Psychiatric Press, 1994.

36 Karterud S, Pedersen G, Engen M, et al: The MBT adherence and competence scale (MBTACS): development, structure and reliability. Psychothe Res 2013;23:705-717.

37 First MB, Spitzer RL, Gibbon M, Williams JB: Structured Clinical Interview for DSM-IV ${ }^{\circledR}$ Axis I Disorders (SCID-I), Clinician Version, Administration Booklet. Washington, American Psychiatric Publishing, 2012.

38 Gibbon M, Spitzer RL, Benjamin LS, Williams JBW. Structured Clinical Interview for DsmIv $^{\circledR}$ Axis II Personality Disorders (SCID-II). Washington, American Psychiatric Publishing, 1997.

39 Wechsler D. Wais-III, Wechsler Adult Intelligence Scale, Third Edition: WMS-III, Wechsler Memory Scale, Third Edition?: technical Manual. Alexandria, Psychological Corporation, 1997.

40 Brooker BH, Cyr JJ: Tables for clinicians to use to convert WAIS-R short forms. J Clin Psychol 1986;42:983-986.

41 Sattler JM: Assessment of Children (ed 3). San Diego, Jerome M. Sattler, Publisher, 1988.

42 Woodbury-Smith MR, Robinson J, Wheelwright S, Baron-Cohen S: Screening adults for asperger syndrome using the AQ: a preliminary study of its diagnostic validity in clinical practice. J Autism Dev Disord 2005;35:331335.
43 Cooke DJ, Michie C, Hart SD, Hare RD: Evaluating the dcreening version of the hare psychopathy checklist-revised (PCL:SV): an item response theory analysis. Psychol Assess 1999;11:3-13.

44 Giesen-Bloo JH, Wachters LM, Schouten E, Arntz A: The borderline personality disorder severity index-IV: psychometric evaluation and dimensional structure. Pers Individ Dif 2010;49:136-141.

45 Sobell LC, Sobell MB: Timeline follow back. A technique for assessing self-reported alcohol consumption; in Litten R, Allen J (eds): Measuring Alcohol Consumption. Psychosoc Biol Methods, Humana Press, 1992, pp 41-72.

46 Gratz KL: Measurement of deliberate selfharm: preliminary data on the Deliberate SelfHarm Inventory. J Psychopathol Behav Assess 2001;23:253-263.

47 Lundh LG, Wångby-Lundh M, Ulander J: Emotional tone in young adolescents' interpersonal relations and its association with deliberate self-harm. Interpersonal 2009;3(suppl 1):111-138.

48 Derogatis LR: Symptom Checklist-90-R: Administration, Scoring and Procedures Manual, ed 3, revised. Minneapolis, National Computer Systems, 1994.

49 Derogatis LR, Lipman RS, Covi L: SCL-90: an outpatient psychiatric rating scale - preliminary report. Psychopharmacol Bull 1973;9: 13-27.

50 Fridell M, Cesarec Z, Johansson M, Malling Thorsen S: Svensk normering, standardisering och validering av symtomskalan SCL-90 [Swedish norms, standardisation, and validation of the symptom scale SCL-90]. Västervik, National Board of Institutional Care (SiS), 2002.

51 Horowitz LM, Rosenberg SE, Baer BA, Ureño $G$, Villaseñor VS: Inventory of Interpersonal Problems: psychometric properties and clinical applications. J Consult Clin Psychol 1988; 56:885-892.

52 Fonagy P, Target M, Steele H, Steele, M: Reflective-Functioning Manual, version 5. Unpublished Manuscript, University College London, UK, 1998.

53 Rudden MG, Milrod B, Target M: The Brief Reflective Functioning Interview. New York, Weill Cornell Medical College, 2005.

54 Rudden M, Milrod B, Target M, Ackerman S, Graf E: Reflective functioning in panic disorder patients: a pilot study. J Am Psychoanalyt Assoc 2006;54:1339-1343.

55 Kazdin AE: Research Design in Clinical Psychology. Boston, Allyn \& Bacon, 2003, p 444.

56 Möller C, Karlgren L, Sandell A, Falkenström F, Philips B: Mentalization-based therapy adherence and competence stimulates in-session mentalization in psychotherapy for borderline personality disorder with co-morbid substance dependence. Psychother Res 2017; 27:749-765. 